\section{Restaurando Viollet-le-Duc. Apontamentos a partir do incêndio na Catedral de Notre Dame de Paris. Um pretexto para falar de métodos} e critérios

\section{Restoring Viollet-le-Duc. Notes from the fire at Notre Dame de Paris Cathedral. A pretext for talking about methods and criteria}

Claudia dos Reis e Cunha* usjt

\section{arq.urb}

número 31 | maio - ago de 2021 Recebido: 05/11/2020 Aceito: $30 / 06 / 2021$

*Arquiteta e Urbanista. Professora associada na Faculdade de Arquitetura e Urbanismo e Design da Universidade Federal de Uberlândia (FAUeD-UFU). Docente permanente do Programa de Pós-graduação em Arquitetura e Urbanismo da UFU (PPGAU-UFU). Docente colaboradora do Mestrado Profissional em Conservação e Restauração de Monumentos e Núcleos Históricos da Universidade Federal da Bahia (MP-CECRE UFBA), claudiareis@ufu.br

\section{Palavras-chave:}

Restauração arquitetônica;

Intervenções em preexistências:

Patrimônio edificado.

\section{Keywords:}

Architectural restoration;

Pre-existing interventions:

Built heritage.

\section{Resumo}

Este texto apresenta apontamentos sobre a necessária restauração da Catedral de Notre Dame, em Paris, em decorrência do incêndio de grandes proporções que atingiu a edificação em abril de 2019. A tragédia que se abateu sobre este importante bem cultural acende um intenso debate rente a possibilidade de uma reconstrucão dov'era, com'era e outras posturas mais coerentes com orientações teórico-metodológicas mais recentes do campo da restauração, indicadas nas Cartas Patrimoniais e recentes do campo da restauração, indicadas nas Cartas Patrimoniais e
outros documentos internacionais. Quando Viollet-le-Duc, juntamente com Lassus, restaurou esta mesma Catedral, na segunda metade do século XIX, os debates não foram menos intensos. E agora cabe ao restaurador do século XXI intervir sobre a obra de Viollet-le-Duc. Quais princípios adotar? Este artigo tem por objetivo, a partir de apontamentos sobre Viollet-le-Duc e a restauração de Notre Dame de Paris, problematizar as questões conceituais e metodológicas em pauta neste século XXI nas intervenções sobre o patrimônio edificado.

\section{Abstract}

This text presents notes about the necessary restoration of the Notre Dame Cathedral in Paris, due to the large fire that hit the building in April 2019. The tragedy that has befallen this important cultural heritage sparks an intense debate about what the paths for its recovery would be, with the possibility of a dov'era, com'era reconstruction and other postures more consistent with more recent theoretical-methodological orientations about restoration, indicated in international conventions and recommendations. When Viollet-le-Duc, together with Lassus, restored this same Cathedral in the second half of the 19th century, the debates were no less intense. And now it is up to the 21st century restorer to intervene on the work of Viollet-le-Duc. What principles to adopt? This article aims, based on notes on Viollet-le-Duc and the restoration of Notre Dame de Paris, to problematize the conceptual and methodological issues on the agenda in this 21 st century in interventions on built heritage. 


\section{Introdução}

Em 15 de abril de 2019 um incêndio de grandes proporções acometeu a Catedral de Notre Dame, localizada na Île-de-France, Paris (Fig. 1). Sem acreditar nas imagens, veiculadas em tempo real em canais de televisão e portais de internet, uma multidão lamentava a provável destruição de um dos símbolos da cidade e da própria França. Monumento Nacional e Patrimônio da Humanidade, a Catedral de Notre Dame é um dos mais visitados monumentos de Paris e sua perda seria um duro golpe contra a identidade de parisienses e franceses, além de um empobrecimento cultural a todos, privados do contato com esse importante bem cultural.

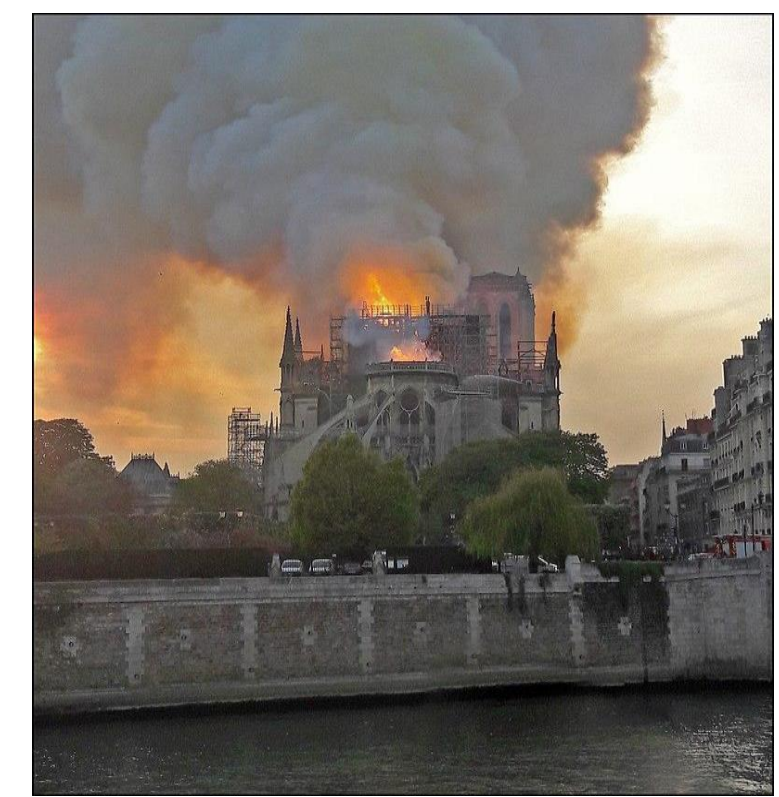

Figura 1. A Catedral de Notre Dame sendo consumida pelas chamas, em 15 de abril de 2019. License: CC-BY-SA-4.0. Disponível em: https://commons.wikimedia.org/wiki/2019_NotreDame_de_Paris_fire\#/media/File:Incendie_Notre-Dame_de_Paris_amont_(cropped).jpg. Acesso em: 05 out. 2020 .

${ }^{1}$ A expressão "dov'era, com'era" ("onde estava, como era") foi cunhada no contexto da reconstrução ao idêntico do campanário de San Marco em Veneza, após seu desmoronamento em 1902. Na mesma noite na qual o campanário veio abaixo, o conselho comunal se reuniu em caráter de urgência, deliberando pela reconstrução com formas idênticas ao original. Essa postura contrariava as noções de restauração de seu tempo, que já condenavam a criação de "falsos históricos" como substitutos de verdadeiras obras de arte e de história. A mesma expressão foi também usada para
Ainda no calor das chamas a reação imediata das autoridades locais é a afirmação categórica - como forma de amenizar a dor acarretada pela ameaça de perda do bem cultural - de sua reconstrução d'ove era, com'era. ${ }^{1}$ Em suas declarações públicas seguidas ao incêndio, o Presidente Emmanuel Macron chegou a afirmar a possibilidade da adoção de "um gesto arquitetônico contemporâneo" capaz de tornar a catedral "ainda mais bela" em seu processo de recuperação. Tais afirmações, ainda que justificadas pela comoção do momento, desencadeiam reações em acadêmicos e estudiosos da restauração, que ponderam sobre as variadas modalidades de intervenção possíveis e a necessidade de uma aproximação crítica e solidamente embasada em princípios do campo disciplinar do restauro, especialmente por se voltar a monumento de tal importância e magnitude (POULOT, 2019, p. 377378).

Enquanto os técnicos e conservadores responsáveis pela edificação ainda analisavam os danos provocados pelo incêndio (Fig. 2), diversas soluções para a recuperação da cobertura e da flecha eram amplamente divulgadas pela rede mundial de computadores. Soluções vanguardistas ${ }^{2}$, tais como um telhado-jardim ou uma piscina na cobertura ou ainda um feixe de luz no lugar da agulha que sucumbiu, somavam-se às vozes mais comedidas ou mesmo bastante conservadoras, para as quais a reconstrução deveria ser adotada, com formas, materiais e técnicas o mais fiéis possíveis às originais. Entre polêmicas e embates, chegou-se a cogitar a realização de um concurso internacional de projeto para a restauração do templo, ideia depois abandonada em favor de uma recuperação "tal qual sua última imagem", renunciando aceitar que um gesto contemporâneo pudesse restabelecer a imagem da catedral na cidade. $\mathrm{O}$ arquiteto Jean Nouvel chegou a afirmar que a restituição da flecha tal como concebida (e realizada) por Viollet-le-Duc no século XIX era um gesto necessário de memória (NOUVEL, 2020). Dominique Poulot sintetiza as diversas posturas assumidas em relação às formas de intervir sobre Notre Dame nesses termos: "A priori a disputa sobre a futura fisionomia da catedral se inscreve em uma disputa entre Antigos e Modernos: reconstruir ou inovar" (POULOT, 2019, p.

caracterizar as inúmeras reconstruções ex-novo de edificações e mesmo de regiões urbanas inteiras que se sucederam ao segundo pós-guerra europeu. A esse respeito, ver: DE FUSCO, 1999.

${ }^{2}$ Algumas dessas soluções podem ser vistas na página: https://www.cartacapital.com.br/mundo/veja-os-projetos-mais-ousados-para-reconstruir-a-catedral-notre-dame/. Acesso em 20 set. 2020. 
377), fazendo alusão à conhecida querela entre Antigos e Modernos estabelecida no seio da Academia francesa de Belas Artes no século XVIII.

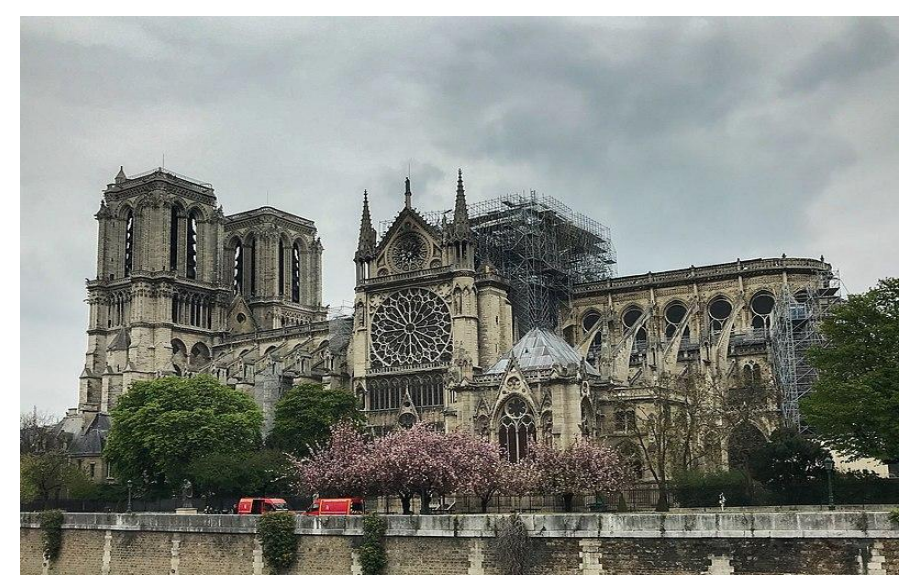

Figura 2. Vista da fachada sul da Catedral de Notre Dame no dia seguinte ao incêndio. License: CC-BY-SA-4.0. Disponível em: https://commons.wikimedia.org/wiki/File:Cathédrale_NotreDame_de_Paris_16_avril_2019.jpg. Acesso em: 05 out. 2020.

Fato é que a tragédia que se abateu sobre este importante bem cultural acende um intenso debate sobre quais seriam os caminhos para sua recuperação. Quando Viollet-le-Duc, juntamente com Lassus, restaurou esta mesma Catedral, na segunda metade do século XIX, os debates não foram menos intensos. E agora cabe ao restaurador do século XXI intervir sobre a obra de Viollet-le-Duc. Quais princípios adotar? Sabe-se que a resposta a essa questão não é simples e nem unívoca, portanto, este artigo tem por objetivo, a partir de apontamentos sobre Viollet-le-Duc e a restauração de Notre Dame de Paris, problematizar as questões conceituais e metodológicas em pauta neste século XXI nas intervenções sobre o patrimônio edificado.

\section{Viollet-le-Duc e Lassus e a intervenção em Notre Dame no século XIX}

Três séculos foram empregados no acabamento desta rainha das catedrais da França, três séculos lançaram, neste grande monumento, tudo o que poderiam

${ }^{3}$ LASSUS, J.-B. et VIOLLET-LE-DUC. Projet de restauration de Notre-Dame de Paris par MM. Lassus et Viollet-le-Duc, rapport adressé à M. le Ministre de la Justice et des Cultes, annexé au projet reunir de mais rico, toda a sua arte, toda a sua ciência. Três séculos, enfim, foram gastos para concluir a obra começada pelo piedoso bispo Maurice de Sully. O monumento estava completo. Por que não o conservar assim? A partir do século XIII, para a igreja de Notre Dame, é apenas uma sucessão de mutilações, de mudanças, sob o pretexto de embelezamentos.

Dessa época, não é tanto o intemperismo que destrói uma bela obra, mas a mão dos homens. (LASSUS; VIOLLET-LE-DUC, apud OLIVEIRA; SANTIAGO, 2019, p. 71$)^{3} \mathrm{~A}$ Catedral de Notre Dame de Paris, edificada entre os séculos XII e XIV incorporando partes de dois outros edifícios religiosos preexistentes, na Île-deFrance, marca a transição do românico ao gótico (OLIVEIRA; SANTIAGO, 2019). Sua grandiosidade marcou o espaço urbano de Paris, tendo sido palco de inúmeros acontecimentos da história francesa, sempre relacionada à associação da Igreja com a Coroa, o que Ihe rendeu consequências devastadoras durante os anos do vandalismo pós-Revolução Francesa (Fig. 3). Vítima privilegiada do iconoclasmo revolucionário (MOREZZI, 2019), o templo católico foi saqueado, usado como depósito de forragens e víveres, sendo cogitada inclusive sua venda como material de construção (VIOLLET-LE-DUC, 1994, p. 46).

Nesse quadro, o florescimento da cultura medievalista e os apelos feitos por Victor Hugo, através da sua Guerre aux démolisseurs e do memorável romance Nossa Senhora de Paris, alavancaram a necessidade de se fazer retornar à dignidade o velho templo injuriado, onde houve episódios aberrantes da sua dessacralização, de transformação em Templo da Razão e, até mesmo, depósito. (OLIVEIRA; SANTIAGO, 2019, p. 34)

Dessa forma, no início do século XIX Napoleão assume com a lgreja romana o compromisso de fazer retornar o culto nas igrejas profanadas, reafirmando, porém que a propriedade desses templos segue sendo do Estado francês, obrigando-o por consequência, a se encarregar de sua restauração.

No prefácio à edição de 1832 do romance Nossa Senhora de Paris, Victor Hugo denuncia a degradação da edificação, sujeita às ações do tempo de abandono, mas, principalmente, à imperícia dos homens "de formação limitada (neoclássica), que à soldo do dinheiro público destroem mais que restauram" (VIOLLET-LE-DUC, 1994, p. 46). As críticas de Hugo voltavam-se a atuação de Godde, arquiteto responsável por trabalhos em Notre Dame, mas que "não tinha boa reputação entre os medievalistas, em virtude de algumas manifestações de imperícia cometidas, anteriormente, em outros monumentos" (OLIVEIRA; SANTIAGO, 2019, p. 34). Dessa 
forma, em 1842, abre-se um concurso público para a restauração do templo, do qual toma parte a dupla Jean-Baptiste Antoine Lassus e Eugéne Emmanuel Violletle-Duc, que é declarada vencedora da concorrência (MOREZZI, 2019, p. 187).

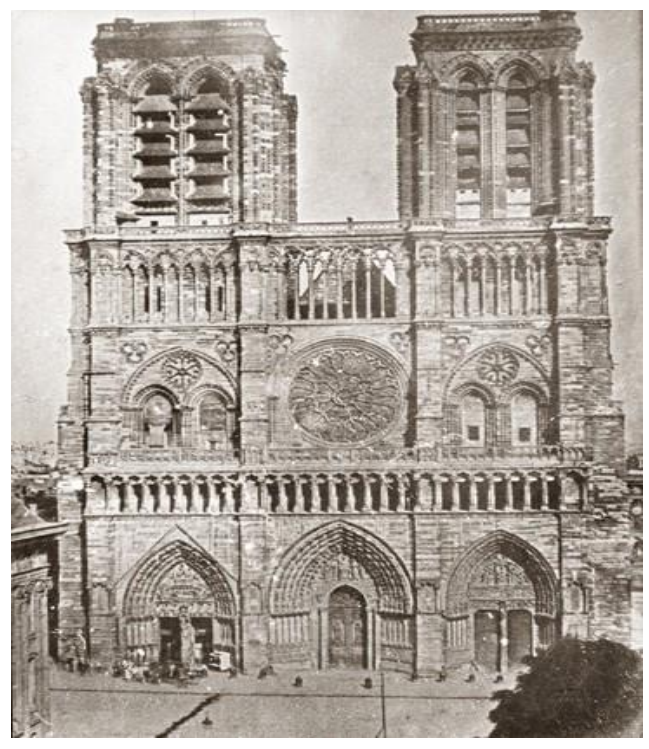

Figura 3. Fachada ocidental da Catedral de Notre Dame antes da campanha de restauro de Lassus e Viollet-le-Duc, daguerreótipo de Noël Paymal Lerebours, 1840. Disponível em: http://www.lusus e Viollet-le-Duc, daguerreótipo de Noël Paymal Lerebours, 1840. Disponível em: http://www.lu-
minous-lint.com/app/image/2195803712147396029963586417/. Acesso em 05 out. 2020. Domínio minous-lint.com/app/image/21958037121473960299635

Lassus, arquiteto formado na École des Beaux-Arts e discípulo de Henri Labrouste, já havia sido encarregado de outras obras de restauração, tendo o jovem arquiteto autodidata Viollet-le-Duc como seu adjunto no encargo das obras na Saint Chapelle (KÜHL, 2007, p. 121). A intervenção na Saint Chapelle se mostrou "uma restauração em que se procurou ser fiel aos documentos e aos indícios existentes e que se constituiu em um verdadeiro laboratório experimental" (VIOLLET-LE-DUC, 2000, p. 13).

${ }^{4}$ LASSUS, J.-B. et VIOLLET-LE-DUC. Projet de restauration de Notre-Dame de Paris par MM. Lassus et Viollet-le-Duc, rapport adressé à M. le Ministre de la Justice et des Cultes, annexé au
Ao apresentarem o projeto de restauro da Catedral de Notre Dame para o Ministro da Justiça e o Serviço dos Cultos, em 1843, Viollet-le-Duc e Lassus (apud GAUSSUIN, 2017, p. 64) ${ }^{4}$ apontam para a necessidade de prudência e discrição nas intervenções, advertindo que uma restauração malconduzida pode acarretar mais danos ao edifício do que a ação do séculos ou os furores populares sobre ele, concluindo que se tratava de esquecer gostos pessoais ou instintos, buscando, no estudo acurado do edifício, seguir o pensamento que presidiu a execução da obra, compreendendo o raciocínio projetual que originou suas formas.

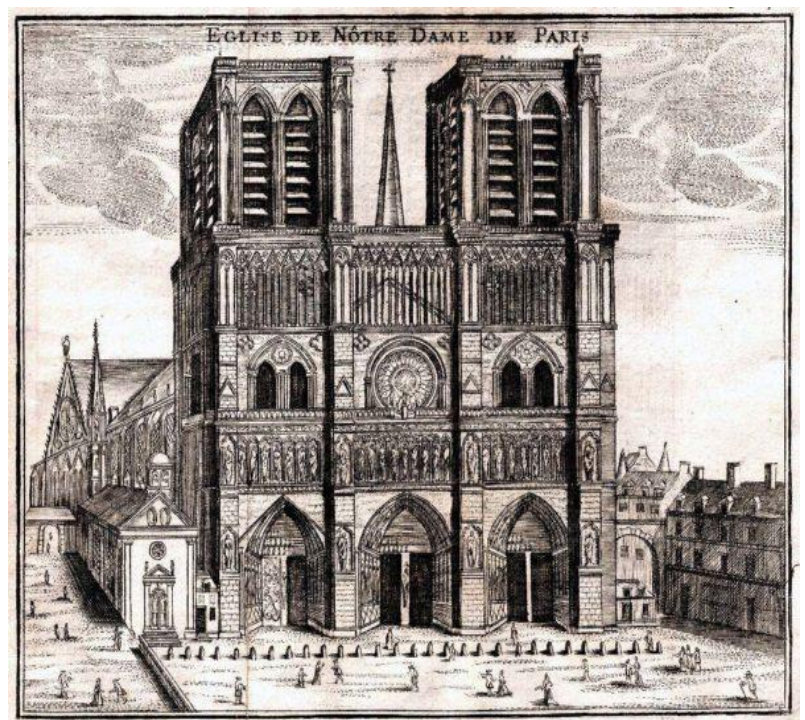

Figura 4. Catedral de Notre Dame em 1776, ainda com a flecha que seria demolida anos depois, em 1792. Disponível em: https://fr.wikipedia.org/wiki/Cath\%C3\%A9drale_Notre-Dame_de_Paris\#/media/Fichier:Paris_1776.JPG. Acesso em: 13 out 2020. Domínio público.

O projeto de Lassus e Viollet-le-Duc para restaurar a catedral de Paris era uma oportunidade fundamental para demonstrar a seus coetâneos as metodologias adequadas para a realização não somente desta obra, mas como paradigma a ser seguido no panorama das intervenções nacionais (MOREZZI, 2019, p. 189). Dessa

projet de restauration remis le 31 janvier 1843. Paris: Imprimerie de Mme Lacombre, 1843. 
forma, os arquitetos explicitam em seu Rapport suas linhas-mestras para conduzir o restauro, preconizando o conhecimento profundo do monumento - em sua realidade concreta e material e através da documentação arquivística textual e iconográfica (Fig. 4) - como ponto nevrálgico para o partido de projeto.

Para Viollet-le-Duc, os testemunhos materiais do passado serviam para satisfazer o desejo do homem de conhecer esse mesmo passado, formando sua história. Esta, por sua vez, serviria de base para forjar expectativas futuras, no caminhar rumo ao progresso ${ }^{5}$. Havia uma visão bastante pragmática e uma fé positivista na relação que propunha com os monumentos históricos. $\mathrm{O}$ arquiteto afirma em seu verbete Restauration que tanto a palavra quanto o assunto são modernos, pois só a partir do século XIX houve o desenvolvimento técnico e a consciência histórica capaz de dar à Restauração o sentido que assumiu à época. Conforme nota a professora Odete Dourado (1994, p. 5), na apresentação de sua tradução do verbete Restauration,

Sua modernidade não reside no fato de se constituir em uma ação projetual sobre preexistências, mas na inserção dessa ação no âmbito de uma nova relação com o passado, relação essa eminentemente moderna.

As intervenções sobre preexistências eram correntes desde épocas remotas, seja por razões de renovação, seja para completar edificações inacabadas ou ainda para melhorias e adequações a novos usos. Em muitos casos, ainda que os autores de tais intervenções as denominassem de restaurações, suas ações estavam imbuídas de uma livre apropriação dos resquícios materiais do passado, que não eram preservados em virtude de suas características estéticas e nem como documentos históricos. A noção de monumento histórico ainda não havia alcançado maturidade para se firmar e guiar os procedimentos sobre as edificações herdadas do passado (CHOAY, 2001, p. 40 e ss).

Os Oitocentos presenciaram um grande desenvolvimento nas diversas ciências, como a Química, a Física, Engenharia, e em relação ao estudo do passado, através da Arqueologia, Filologia e de uma nascente História da Arquitetura, que como a

${ }^{5}$ Esse pensamento era compartilhado com Lassus, que, conforme apresenta Napoleone (2019, p. 243. Tradução nossa): "Lassus é, com Merimée, aquele que, mais que todos, foi próximo a Violletle-Duc em seu caminho inicial no mundo do restauro". Os escritos de Lassus e Viollet-le-Duc, difundidos em sequência de artigos publicados no periódico "Annales Archéologiques", dirigido por própria História se firmava como campo científico e disciplinar. Além desse desenvolvimento técnico, para Viollet-le-Duc (2000, p. 32),

O nosso tempo, e somente o nosso tempo, desde o começo dos séculos históricos, tomou, em face do passado, uma atitude inusitada. Quis analisá-lo, comparálo, classificá-lo e formar sua história, seguindo passo a passo a marcha, os progressos, as transformações da humanidade.

Ou seja, a análise e o estudo do passado estavam em íntima relação com o caminhar rumo ao futuro: "nosso tempo não se contenta em lançar um olhar perscrutador por trás de si: esse trabalho retrospectivo apenas desenvolve os problemas colocados no futuro e facilita a sua solução. É a síntese que se segue à análise." (VIOLLET-LE-DUC, 2000, p. 34). A despeito da admiração profunda que Viollet-le-Duc manifestasse em relação à arquitetura medieval, a atitude do arquiteto em nada se assemelhava à nostalgia ou saudosismo, muito ao contrário. O estudo das arquiteturas do passado em geral e da medieval em particular seria a fonte para necessária renovação da arte do seu tempo. Na produção arquitetônica medieval estaria a chave para a compreensão dos verdadeiros princípios sobre os quais deveria se assentar a disciplina arquitetônica do século XIX, tornando possível "reabilitar a arte", como escreve Lassus (apud NAPOLEONE, 2019) ${ }^{6}$. Compreender, de modo complexo e profundo, o sistema racional e lógico dessas arquiteturas do passado medieval era passo fundamental para o desenvolvimento da própria arquitetura oitocentista, daí a importância capital que remanescentes dessa época fossem conservados e restaurados.

Tal estrada em direção à fonte, em direção à origem, é percorrida tendo como guia a razão, que terá como cômpito demonstrar a superioridade da arte medieval sobre aquela antiga [clássica] do ponto de vista das proporções, das decorações e da construção, e utilizando os instrumentos da história e da arqueologia. (NAPOLEONE, 2019, p. 244. Grifos no original. Tradução nossa)

Como documento, cada monumento a ser restaurado, deveria, na doutrina de Viollet-le-Duc, ser pormenorizadamente analisado e estudado antes de qualquer intervenção. Esse conhecimento aprofundado sobre o monumento daria então ao

Adolphe Napoléon Didron, confirmam as aproximaç̃es conceituais entre ambos, sendo difícil determinar quem influencia quem (NAPOLEONE, 2019).

${ }^{6}$ LASSUS, J.-B.-A. De L'art et de l'Archéologie, in Annales Archéologiques, aprile 1845, p. 198. 
arquiteto-restaurador instrumentos para compreender a concepção original do projeto, e daí, a autoridade para intervir. Nas palavras de Lassus e Viollet-le-Duc (apud OLIVEIRA; SANTIAGO, 2019, p. 58) ${ }^{7}$ :

Não se deve hesitar nem fazer experiências, mas marchar com passo firme, não arriscar, ter sucesso, enfim. Para chegar a esse resultado, é necessário decifrar os textos, consultar todos os documentos que existam sobre a construção deste edifício, tanto descritivos quanto gráficos, estudar, sobretudo, as características arqueológicas do monumento, a fim de recolher as tradições frequentemente tão preciosas.

E era munido dessa autoridade que Viollet-le-Duc agia nas restaurações de que era encarregado, em ações francamente intervencionistas. A análise precisa e rigorosa, como nos estudos científicos, daria ao restaurador respostas unívocas e inquestionáveis, não apenas sobre qual o estado real da obra, mas a respeito da intenção do construtor primitivo, dessa maneira - acreditava Viollet-le-Duc - ao restaurador caberia apenas revelar o "estado completo que pode não ter existido nunca em um dado momento" (VIOLLET-LE-DUC, 2000, p. 29).

Porém, reduzir a obra de Viollet-le-Duc à mera reconstituição de formas ou a uma busca intransigente da unidade estilística não faz jus à figura do arquiteto, dado que sua aproximação com os monumentos do passado, imersa na cultura oitocentista e suas contradições, seja muito mais complexa e nuançada (OLIVEIRA; SANTIAGO, 2019, p. 24). De fato, é inegável que em suas obras de restauração - não apenas em Notre Dame - a reintegração estilística seja real e vá se tornando cada vez mais franca e eloquente ${ }^{8}$. Deve-se argumentar, no entanto, que para Viollet-le-Duc, não era a autenticidade material a qualidade primeira a se perseguir nas restaurações, mas a recuperação de uma capacidade de comunicação inerente à obra arquitetônica, que só seria possível em seu estado completo. De onde deriva a distinção entre a intervenção para ruínas arqueológicas e aquelas voltadas à arquitetura:

[...] aos olhos de Viollet-le-Duc, o monumento que tem a sua frente não é só uma relíquia arqueológica a conservar ou consolidar, mas uma arquitetura que deve

${ }^{7}$ LASSUS, J.-B. et VIOLLET-LE-DUC. Projet de restauration de Notre-Dame de Paris par MM. Lassus et Viollet-le-Duc, rapport adressé à M. le Ministre de la Justice et des Cultes, annexé au projet de restauration remis le 31 janvier 1843. Paris: Imprimerie de Mme Lacombre, 1843.

${ }^{8} \mathrm{O}$ próprio E. E. Viollet-le-Duc em seu verbete restauração afirma que: "sob sua [Merimée] inspiração sábia, sempre submetida a uma crítica severa, que foram empreendidas restaurações, de início manter a própria relação com o mundo e falar à contemporaneidade. Quando mutilada, a arquitetura perde seu próprio sentido mais profundo porque não é mais capaz de transmitir a própria mensagem a não ser aos iniciados, historiadores e arqueólogos, mas não ao resto dos cidadãos. A tutela, diferentemente, nasce na França para fins civis: os monumentos históricos eram concebidos como materialização da história da nação e os destinatários de sua conservação eram os próprios cidadãos. (NAPOLEONE, 2019, p. 252. Tradução nossa)

Dessa forma, a reconstituição do estado completo da obra (ainda que este não tenha nunca existido), era condição fundamental para que a restauração atingisse seu objetivo de tornar a dar voz a essas estruturas arquitetônicas, que desempenhariam, assim, sua função propedêutica na sociedade:

Somente completa, a arquitetura pode falar a todos e desenvolver aquele espírito crítico que era, desde seu nascimento, o verdadeiro objetivo da tutela dos monumentos históricos e da criação das coleções museais abertas ao público. A completude é fundamental para esse escopo (a inteligibilidade da arquitetura). (NAPOLEONE, 2019, p. 253. Tradução nossa)

Essa visão de restauração arquitetônica identificada com a completude das formas e a integridade estilística não era exclusiva de Viollet-le-Duc, tendo grande ascendência entre muitos estudiosos e eruditos de seu tempo, entre os arquitetos que integravam os serviços da Comissão dos Monumentos Históricos na França e mesmo em outros países europeus, como a Inglaterra e a Alemanha (VIOLLET-LEDUC, 2000, p.19-20). Como afirma Poisson (2019, s/p. Tradução nossa), "essa preocupação com a conservação não era a do século XIX e muito menos a de Violletle-Duc. O que era importante para ele era restaurar a integridade da arquitetura gótica, sua dignidade, sua beleza, seu valor exemplar".

As soluções adotadas por le-Duc e Lassus para a Catedral de Paris têm como finalidade primeira, portanto, contemplar a prescrição de que "cada edifício ou cada parte de um edifício devam ser restaurados no estilo que lhes pertence, não somente como aparência, mas como estrutura." (VIOLLET-LE-DUC, 2000, p. 47). Justamente a noção de estilo ${ }^{9}$ - fundamental no pensamento leduciano - ampara as

com uma grande reserva, logo em seguida com mais ousadia e de maneira mais abrangente." (VIOLLET-LE-DUC, 2000, p. 44. Grifos nossos).

${ }^{9}$ Longe de se relacionar simplesmente às formas de uma obra ou a um decorativismo, o estilo para Viollet-le-Duc se configura como um sistema lógico-racional no qual materiais, formas e estrutura se articulam, configurando-se como "manifestação de um ideal fundado sobre um princípio" (VIOLLET- 
tomadas de decisão da dupla e, após a morte de Lassus em 1847, de Viollet-le-Duc como único chefe no canteiro de obras durante os vinte anos de intervenção restaurativa em Notre Dame. Ora propondo a repristinação de formas e elementos perdidos tal como teriam sido, como no caso do conjunto escultórico da fachada ocidental (Fig. 5), ora acrescentando ou redesenhando soluções com novas formas e materiais, tal como as gárgulas ou a flecha, perdida em 1792 e restituída com novo perfil e materiais contemporâneos (Fig.6) (GAUSSIN, 2017; MOREZZI, 2019). A adoção de posturas distintas não se configura como contraditória, mas está justamente amparada na busca por evidenciar o verdadeiro estilo da Catedral, dotando-a da capacidade de comunicar novamente sua verdade construtiva, que se havia perdido, seja pelas transformações espúrias impostas a ela ao longo dos séculos, seja pela desagregação ou decadência de sua matéria.

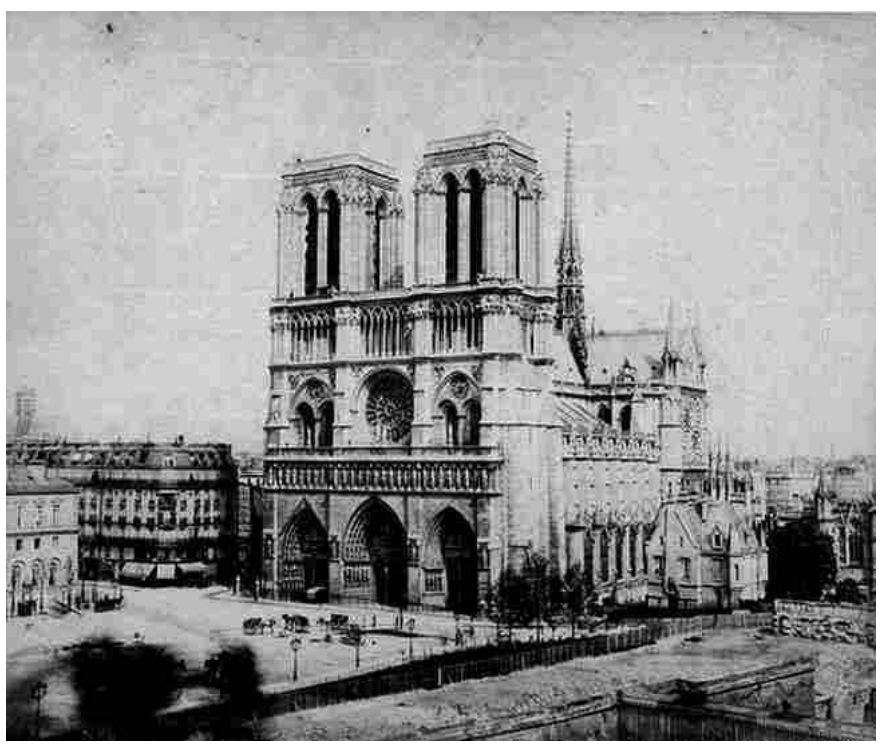

Figura 5. Catedral de Notre Dame por volta de 1865, apresentada já em seu "estado completo que pode não ter existido nunca em um dado momento". Disponível em: http://en-noir-et-blanc.com/Notre-Dame\%20et\%201\%27\%C3\%AEle\%20de\%20la\%20Cit\%C3\%A9-id12546.html. Acesso em: 13 out. 2020. Domínio público.

LE-DUC, 1994, p. 46). Dessa forma, "a arquitetura terá um estilo quando não se configure como uma banal arte de imitação, mas seja capaz de transcender a complexa série de observações tiradas da natureza e da arquitetura do passado e compor uma obra nova unitária, verdadeira, racional,

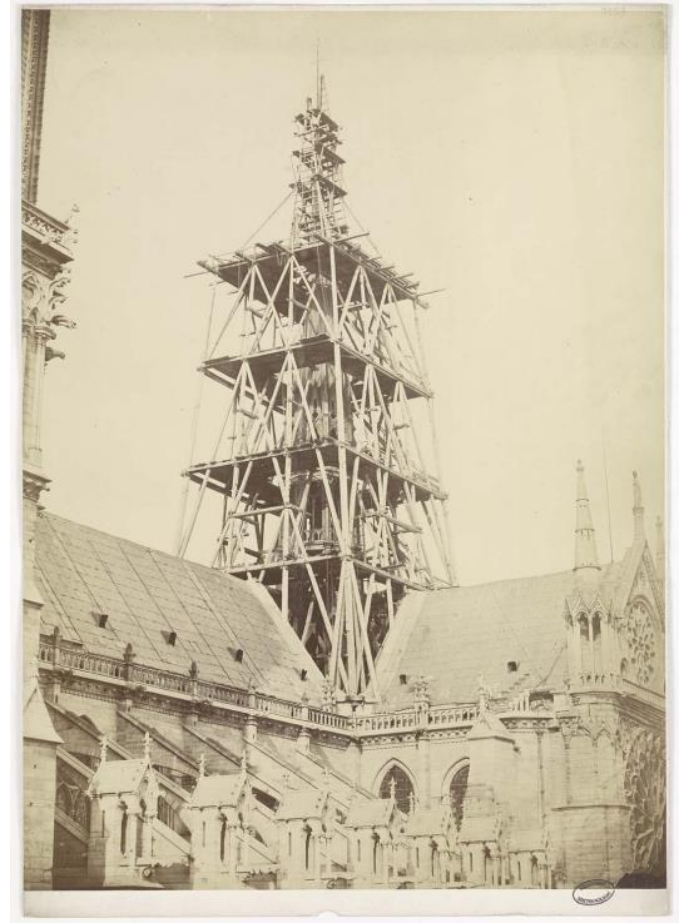

Figura 6. Catedral de Notre Dame com a flecha em construção em fotografia de Bissons Frères, 1857. Fonte: Ministère de la Culture (France), Médiathèque de l'architecture et du patrimoine, diffusion RMN-GP. Domínio público

Como afirma Morezzi (2019, p. 198. Tradução nossa), "A catedral de Notre Dame, após os trabalhos de restauro, pôde tornar a representar o símbolo da cidade que Victor Hugo havia descrito poucos anos antes".

[...] a restauração de Notre-Dame de Paris por Lassus e Viollet-le-Duc pode ser vista como o esforço de renascimento, em sua própria identidade, de um símbolo maior da História e da restauração de uma paisagem nacional, em sentido amplo […]. (POISSON, 2019, s/p. Tradução nossa)

Ainda assim, as críticas também ressoaram. Nas duas décadas ao longo das quais se desenrolaram as obras no templo, esse assunto moderno, tal como observado

lógica" (NAPOLEONE, 2019, p. 246. Tradução nossa), de onde descende as críticas do arquiteto à produção eclética vigente em sua época e sua persistente busca por um estilo verdadeiramente adequado ao seu tempo. 
acuradamente pelo próprio le-Duc, havia ganhado novos contornos e os embates entre posturas mais voltadas à conservação e outras mais pendentes à recuperação em estilo se intensificaram. A despeito do reconhecimento e dos numerosos seguidores que Viollet-le-Duc obteve não apenas na França, como também em diversos outros países europeus, vozes discordantes já entre seus contemporâneos se levantaram contra seus métodos e lamentaram a perda da originalidade dos monumentos por ele restaurados (JOKILEHTO, 1986; GAUSSUIN, 2019; KÜHL, 2017).

Desde o último quartel do século XIX, a hegemonia da doutrina de Viollet-le-Duc começa a ser abalada por uma postura mais questionadora, mais nuançada, mais informada também, graças aos progressos da arqueologia e da história da arte. Essa orientação foi sendo posta em prática paulatinamente, de forma anônima e quase furtiva. (CHOAY, 2001, p. 164)

As polêmicas sobre os parâmetros e métodos mais idôneos para se intervir sobre os monumentos históricos, que envolveram discussões apaixonadas durante toda a segunda metade do século XIX, contribuíram para conformar a noção atual de restauração, cuja face parece ainda não ser tão nítida, como se depreende das discussões em torno da nova restauração a ser empreendida em Notre Dame neste século XXI.

\section{Um restauro do século $X X I$}

A necessária intervenção na catedral de Notre Dame após o traumático incêndio de 2019 deu margem a diversas posturas em relação aos caminhos possíveis para recuperar suas feições danificadas com o sinistro, bem como devolver-lhe ao uso como templo e como monumento. Nesse embate, de um lado aqueles que defendem sua restauração seguindo critérios e métodos oriundos das mais atuais posturas do campo da restauração e, de outra parte, aqueles que postulam um simples retorno às formas perdidas. E há ainda uma outra vertente que vê na catástrofe que se abateu sobre este importantíssimo patrimônio da humanidade uma ocasião para a manifestação plena das potencialidades da arquitetura contemporânea, sem compromisso efetivo com a conservação e a restauração, configurando-se como oportunidade de um exercício projetual novo sobre a preexistência.

${ }^{10} \mathrm{~A}$ questão da reconstrução após perdas traumáticas segue um ponto de amplo debate no seio das instituições de tutela do patrimônio cultural, tais como o ICOMOS e o ICCROM. Em 2017, após um
Diante deste quadro heterogêneo delineado brevemente acima, seria importante deter-se sobre cada uma dessas posturas e refletir criticamente sobre seus significados sociais no século XXI e suas consequências para a preservação deste bem cultural que - por seu reconhecimento - não pertence apenas ao povo francês, mas a todos nós. Como adverte Dominique Poulot (2019, p. 379. Tradução nossa):

[Ao] Responder ao desastre não se pode economizar em reflexão coletiva sobre as justificativas e razões para a manutenção de uma catedral em um Estado laico, entre práticas religiosas e práticas culturais, rótulos patrimoniais e individualismo democrático, comunidade nacionais e finalmente mundiais.

As reconstruções dov'era, com'era encontram eco e ressoam nos clamores populares desde o início do século XX, chegando ao tempo presente como uma real possibilidade frente à destruição traumática de bens com forte significação social e memorial. ${ }^{10}$ Foram inúmeras as intervenções em monumentos, parcial ou totalmente destruídos, nas quais se operou com a reconstrução buscando devolver uma imagem perdida, sendo a reconstrução do centro de Varsóvia após a Segunda Guerra Mundial a mais paradigmática, mas longe de ser a única.

A necessidade de reparação, a recuperação de uma identidade calcada nos remanescentes materiais, ou ainda como marco simbólico de superação de um povo diante de uma tragédia, estão entre as muitas justificativas para a adoção desta postura de reconstruir, que, por sua vez, não está isenta de muitas contradições.

Na confluência das possibilidades de reconstrução (como era antes do incidente) e da restauração (enquanto uma ação cultural) se estabelecem questionamentos circunscritos sobre a forma de intervir na matéria, entendida enquanto documento e enquanto suporte de uma imagem que se pretende resgatar. (RODRIGUES, 2017, s.p.)

Ainda que reconheçam em muitos casos a legitimidade das reconstruções como forma de reparação, especialmente quando a perda do bem é total, seus críticos argumentam que o objeto reconstruído teria - no máximo - um valor pedagógico ou rememorativo, não devendo ser confundido com a obra original perdida (BRANDI, 2004; PANE, 1950).

colóquio que reuniu representações de diversos países, o ICOMOS lançou o documento "ICOMOS Guidance on Post Trauma Recovery and Reconstruction for World Heritage Cultural Properties" (ICOMOS, 2017) 
Os defensores da necessidade de restauração de obras danificadas ou lacunosas, entendida como ato circunscrito no âmbito de uma disciplina com metodologias e critérios de ação próprios, argumentam que a noção (especialmente ocidental) de monumento histórico está ancorada na impossibilidade de repetição ou de retorno. O tempo na concepção de matriz judaico-cristã é linear e não volta (KÜHL, 2016). Cada evento histórico é único e irrepetível, assim como são os bens culturais, testemunhos únicos de um dado momento histórico em um dado contexto cultural (ICOMOS, 1964, 2004). Nesse sentido argumentam os críticos da reconstrução, indicando que esta ação se configuraria como ato que não pertence ao campo da restauração, para o qual a obra reconstruída seria um falso histórico e um falso estético, não podendo jamais substituir o bem que se havia perdido.

O adágio nostálgico 'como era, onde estava' é a negação do próprio princípio da restauração, é uma ofensa à história e um ultraje à Estética, colocando o tempo como reversível e a obra de arte como reproduzível à vontade. (BRANDI, 2004, p. 89).

Longe de reconstruir ou restabelecer à l'identique as formas perdidas, o objetivo das intervenções sobre os bens culturais, tal como se afirmou paulatinamente desde finais do século XIX conformando a atual concepção de restauração, busca restituir a unidade potencial da obra, isto é, desenvolver a partir das sugestões oferecidas pela própria obra e sua atenta análise, os elementos capazes de reintegrar a obra lacunosa em um aspecto digno, possibilitando sua apreciação e fruição (CARBONARA, 1978). Nesta proposição, a restauração só seria possível se a obra de arquitetura ainda mantivesse ao menos parcialmente suas qualidades estético-figurativas, caso esta fosse rompida totalmente dado o grau de destruição alcançado, seria impossível restaurá-la. O limite entre a possibilidade ou não de restaurar uma obra danificada seria, portanto, avaliar acuradamente se ela permanece - mesmo mutilada - uma arquitetura, ou se, ao contrário, tornou-se ruína ${ }^{11}$.

Ao argumento principal que o valor absoluto da obra destruída, aquele da arte, perdeu-se e não é mais recuperável, somam-se a inutilidade e, se poderia dizer, a imoralidade de seguir com um restauro que é um verdadeiro e próprio falso

${ }^{11}$ As ruínas configuram-se como caso limite para a ação do restaurador, na qual a restauração "só pode ser a consolidação e conservação do status quo, ou a ruína não era uma ruína, mas uma obra que ainda continha uma vitalidade implícita para promover uma reintegração da unidade potencial originária" (BRANDI, 2004, p. 65). Nesse caso, a ação do restaurador deve concentrar-se em "uma estético-histórico, cultural e documental, e que como tal não pode enriquecer a nossa alma e a nossa consciência, não podendo recriar o passado; é um ato, portanto, sob todos os aspectos, anti-histórico e vão. (BONELLI, 1995, p. 24. Tradução nossa)

Ao voltar os olhos para a Catedral de Notre Dame após o incêndio de 2019, podese perceber que a despeito dos danos na cobertura e na perda total da flecha, a edificação mantém sua estrutura e forte presença urbana, sendo, dessa forma, plenamente enquadrável como caso a ser efetivamente restaurado. A discussão seria justamente, no caso em questão, definir quais as formas para a reintegração da imagem lacunosa do monumento. Uma nova cobertura deve ser proposta. Não necessariamente copiando a cobertura destruída pelo fogo, ao contrário, guiando-se pelas prescrições atuais do campo da restauração, o restaurador do século XXI deveria ancorar-se no tripé: distinguibilidade, compatibilidade físico-química e retrabaIhabilidade (CARBONARA, 2012). Tais postulados podem ser observados já em 1964 no documento síntese do II Congresso Internacional de Arquitetos e Técnicos dos Monumentos, a muito conhecida Carta de Veneza, na qual a restauração é assim definida:

Art. 9: A restauração é uma operação que deve ter caráter excepcional. Tem por objetivo conservar e revelar os valores estéticos e históricos do monumento e fundamenta-se no respeito ao material original e aos documentos autênticos. Termina onde começa a hipótese; no plano das reconstituições conjeturais, todo trabalho complementar reconhecido como indispensável por razões estéticas ou técnicas destacar-se-á da composição arquitetônica e deverá ostentar a marca do nosso tempo. (ICOMOS, 1964, 2004, p.93. Grifos nossos)

Se à época das intervenções propostas por Le-Duc e Lassus, as críticas às restaurações em estilo se fizeram sentir, os postulados de uma ação para restaurar a Catedral hoje não podem ignorar esses quase dois séculos de discussões e amadurecimento na compreensão do papel dos monumentos na sociedade e, especialmente, dos compromissos deontológicos que o restaurador deve ter em intervenção de tamanha responsabilidade. De fato, mesmo na pluralidade de posições dentro do campo da restauração (sempre existente, deve-se deixar claro), nas últimas

intervenção indireta que concerne ao espaço-ambiente da ruína" (BRANDI, 2004, p. 66). Princípio reafirmado pela Carta de Veneza em seu artigo 15, que diz: "Devem ser assegurados o ordenamento das ruínas e as medidas necessárias à conservação e proteção permanentes dos elementos arquidas ruinas e as medidas necessárias a conservação e proteção permas
tetônicos e dos objetos descobertos" (ICOMOS, 1964, 2004, p. 94). 
décadas alguns consensos foram sendo paulatinamente alcançados, reconhecendo os bens culturais como portadores de valores histórico-documentais e estético-formais, que devem ser conservados com a finalidade de sua fruição no presente e transmissão ao futuro de modo o mais íntegro possível.

[...] o intenso debate dos últimos decênios e a consequente circulação das ideias produziram, pelo menos na Itália, profícuas trocas e contaminações que - mesmo nas diferenças conceituais - parecem fazer ver um desenvolvimento ulterior das teorias do restauro em direção a uma aproximação menos maniqueísta desde há alguns anos. Não se trata ainda de uma nova "doutrina", em grau de superar as precedentes - como profetizava Bonelli frente à contraposição entre restauro crítico e pura-conservação (BONELLI, 1986) - mas certamente de uma evolução em sentido mais conservativo nos confrontos com a matéria antiga da parte de todas as correntes, juntamente com um progressivo afirmar-se do critério da distinguibilidade mesmo entre os fautores da orientação menos inclinada a reconhecer sua validade, como aqueles da "manutenção-repristinação". (PANE, 2017, p. 127. Tradução nossa)

Obviamente, admite-se que para a restauração de Notre Dame não exista uma solução única possível. A máxima propalada de que cada caso é um caso e que, conforme já advertia Viollet-le-Duc, "princípios absolutos nessas matérias podem conduzir ao absurdo" (VIOLLET-LE-DUC, 2000, p. 50), deve estar clara. Porém, essa pertinência sempre relativa das soluções de restauro não pode ser confundida com permissividade ou levar a considerar que qualquer ação sobre os bens culturais possa ser considerada preservação (KÜHL, 2016).

Nesse momento, parece oportuno analisar uma última posição frente à recuperação dos danos sofridos pela Catedral de Notre Dame, que seria aquela de um exercício projetual novo sobre a preexistência, capaz de expressar plenamente a linguagem contemporânea da arquitetura. Negando uma reconstrução estilística "dov'era, com'era" e também uma prudente intervenção restaurativa, os fautores desta aproximação defendem uma maior liberdade na apropriação das arquiteturas do passado, num processo de intervenção que - incorporando e dialogando com os remanescentes históricos - produziria uma nova arquitetura, plenamente contemporânea. Reside nessa postura a alegação de que a cultura arquitetônica contemporânea tem o direito de deixar suas marcas no território e na imagem das cidades, tal como os arquitetos do passado tiveram (Ignasi de Solá Morales em Hernández Martínez, 2016).

Se, num primeiro momento, a postura dos arquitetos de deixarem sua marca na obra, garantindo a distinguibilidade entre a matéria original e aquela acrescida através da intervenção parece apontar para uma convergência com o pensamento da restauração, um olhar mais acurado demonstrará claramente a divergência entre ambas: o ponto de partida e foco central da preservação está no monumento, que, ao contrário, é entendido pelos arquitetos contemporâneos como um cenário de fundo ou mote para elaboração de sua proposição projetual. A diferença parece ser, portanto, a de projetar na pré-existência e para a pré-existência, cujo desdobramento prático é totalmente distinto em um caso e noutro. O compromisso primeiro do restaurador, ainda que se valha (necessariamente) da criatividade e inovação nas soluções para o tratamento das lacunas, é com a conservação do bem cultural, na sua materialidade e conformação física. Isso exige competência projetual antes de mais nada, mas não dá ao arquiteto restaurador plena liberdade de ação, sua criatividade deve estar sempre subordinada ao objetivo da conservação e transmissão ao futuro do bem cultural. Não se trata, portanto, de um gesto personalista, tal como reivindicado pelos arquitetos críticos da restauração, tornando flagrante a distinção entre posturas que pareceriam - num olhar mais superficial - assemelhadas.

Muitos são os arquitetos hoje que criticam o que consideram um protecionismo excessivo, que imobiliza e impede o pleno desenvolvimento das potencialidades da arquitetura contemporânea. Apenas para ilustrar, cita-se a exposição Cronocaos, organizada pelo arquiteto holandês Rem Koolhaas para a 12ª Exposição Internacional de Arquitetura da Bienal de Veneza, de 2010, na qual tecia duras críticas a organismos como a UNESCO, que com suas políticas de conservação do patrimônio estariam destruindo as cidades, produzindo gentrificação e exclusão social (HERNÁNDEZ MARTÍNEZ, 2016, p. 34). Corroborando as provocações feitas por Koolhaas, o arquiteto espanhol Andrés Cánovas (apud HERNÁNDEZ MARTíNEZ, 2016, p. 34) ${ }^{12}$, afirma que:

Os termos reabilitação e conservação se apresentam como grapas que fixam as atuações a uma realidade sobre o existente: devolver a construção a seu estado 
original - como se isso fosse desejável ou possível -, ou, em seu caso, aplicar-

Ihe o clorofórmio da estabilização.

Tais posturas revelam, de um lado, uma completa incompreensão dos preceitos da restauração, apresentada ainda em sua face oitocentista, de retorno ao estado originário ou como um embalsamamento da obra, visando uma imutabilidade de sua imagem (o que a restauração denuncia como impossibilidade óbvia). De outra parte, a defesa da plena liberdade de expressão arquitetônica, feita nesses termos, de direito de continuidade ou legítima expressão do genius criador contemporâneo, remonta aos tempos mencionados por Viollet-le-Duc, que com arguta compreensão afirmava que, desde eras imemoriais os homens intervinham em edificações herdadas do passado, no entanto, nenhum deles praticava restauro, já que destituídos de uma compreensão histórico-crítica na análise dessa herança (VIOLLET-LE-DUC, 2000).

Não se pode negar que a cultura arquitetônica contemporânea pode sim produzir obras de muita qualidade plástica e plenamente capazes de desempenhar suas funções sociais, inclusive quando age sobre preexistências de valor cultural, porém, no caso de intervenções em bens culturais não se pode arriscar e depender da visão projetual de um único arquiteto ou escritório de arquitetura. Ser mais ou menos incisivo nas modificações do tecido figurativo da obra não pode ser fruto simplesmente de um partido de projeto, dado que tais escolhas poderiam comprometer o direito de todos à fruição do bem cultural em sua plenitude - como documento histórico e como fato estético. Como afirma Carbonara (2012), a cultura do restauro não pode e não deve estar apartada da cultura arquitetônica de seu tempo, todavia, ainda que se constitua como atividade inerente ao fazer arquitetura, o restauro arquitetônico não segue regras próprias, autônomas em relação aos postulados disciplinares da restauração em geral, ao contrário, deveria a ele se submeter.

Soluções pertinentes ao campo do restauro devem ser balizadas por aquilo que motiva a preservação, entendida como ato de cunho ético-cultural, e pelos princípios de intervenção que derivam disso. Analisar a fundamentação teórica do restauro, em suas várias vertentes e transformações ao longo do tempo, é essencial para o entendimento mais pleno das formulações, de modo a interpretá-las para os casos específicos, justamente para que a ação não seja arbitrária, mesmo devendo ser sempre problematizada. (KÜHL, 2016, p. 54)
Ainda que o debate teórico sobre a restauração seja mais afeito à cultura italiana, as cartas e recomendações internacionais indicam também caminhos para um debate que tem fronteiras bem mais vastas. Nesse sentido, diversos estudiosos franceses, ao lado do Comitê francês do ICOMOS e outras entidades ligadas à conservação do patrimônio chamam à atenção para o necessário respeito aos postulados da Carta de Veneza e de Cracóvia (GALLET, 2019, p. 215), assim como o diálogo com os membros do Comitê do Patrimônio Mundial (UNESCO, 2019).

\section{Considerações finais}

Lassus e Viollet-le-Duc, ao defenderem seu partido de projeto no Rapport endereçado ao Ministro, tinham clareza da importância de seu trabalho e desejavam que a restauração da Catedral de Notre Dame de Paris se tornasse um modelo a ser seguido em futuras intervenções. Da mesma forma, o restauro do templo danificado hoje pode, com todas as delicadas decisões que se devem tomar, se constituir numa oportunidade excepcional e paradigmática de demonstrar os compromissos da sociedade contemporânea com a história da restauração e esses restauradores do passado. A presidência do ICOMOS manifestou-se no sentido de que de fato a restauração da catedral se constituiria numa oportunidade sem precedentes de estudos e aprendizado, que pode ser sintetizada na expressão: "Um edifício quase único, portanto, responde a uma organização quase única de pesquisa e coordenação também" (ICOMOS France, 2020, p. 10).

Entretanto, o compromisso dos restauradores deste nosso século XXI com os restauradores do passado não pode significar uma subserviência aos seus métodos ou preceitos de ação, ao contrário, fazer jus à Viollet-le-Duc significa um mergulho profundo na contemporaneidade, compreendendo o papel que os bens culturais têm na sociedade atual e daí tirar os parâmetros de ação. Viollet-le-Duc era, antes de mais nada, um homem de seu tempo, profundamente comprometido com sua realidade social, uma lição importantíssima para a contemporaneidade.

Toda e qualquer ação de restauro deve ter os olhos no presente, pois é ao seu próprio tempo que deve dar respostas. E, muitas vezes, as respostas fáceis e imediatistas trazem equívocos e comprometem a possibilidade de usufruto do bem cultural, comprometendo o direito do presente e, consequentemente, do futuro. Sendo assim, não se pode deixar de sublinhar a responsabilidade que a conservação tem com as próximas gerações, que merecem, como as que vieram antes de nós e 
como a nossa, contemplar a rainha das Catedrais da França em sua plenitude e autenticidade, sem negar todas as suas glórias e tragédias. A restauração não deve reescrever a história do monumento, apagando as marcas indesejáveis da tragédia como forma de acalmar nosso espírito, mas nele acrescentar mais uma camada temporal, revelando seu devir no tempo.

Olhar para a história de Notre Dame, com suas vicissitudes plurisseculares, pode auxiliar numa reflexão menos apaixonada e mais calcada nos instrumentais que as teorias da restauração têm a oferecer na atualidade, em grande medida justamente em razão da atuação e dos escritos de Viollet-le-Duc, aos quais cabe à contemporaneidade se deter.

Contemplar a obra e os textos de Viollet-le-Duc e seu legado para o campo da restauração, compreendendo aquele contexto cultural e social específico tão diverso do atual, pode fornecer mais do que métodos ou fórmulas para a atuação, configurando-se como baliza para a compreensão da restauração como ato cultural, que deve responder ao presente e ao futuro na restauração que está por vir.

Justamente as cartas de restauro desde 1931 até hoje sempre condenaram o restauro de invenção, recomendando de deixar os traços da passagem do tempo de modo a não trair a autenticidade do monumento. Mas todas as recomendações perdem força diante do sentimento de imediato, do desejo de cancelar as cicatrizes com um golpe de bisturi: cada restauro como aquele que se volta à Notre Dame necessitaria de uma pausa de silêncio e de reflexão, que não se conciliam com os tempos difíceis da política hodierna de proclamação. (IRACE, 2019, s/p. Tradução nossa)

Ao estabelecer um prazo de cinco anos para as obras de intervenção em Notre Dame, o poder público explicita seu desejo de dar respostas rápidas à população que demanda reparação diante do sinistro. Porém, a complexidade do canteiro de trabalho e a avaliação precisa do estado atual da estrutura remanescente aponta para a necessidade de cautela, como se denota do relatório anual do ICOMOS France ( $(2020$, p. 8). Os tempos da restauração não são os tempos dos apelos midiáticos, ainda que o patrimônio certamente seja na contemporaneidade um dos eixos privilegiados do mercado de consumo dos bens culturais.

\section{Referências}

BRANDI, Cesare. Teoria da restauração. São Paulo: Ateliê Editorial, 2004.

BONELLI, Renato. Scritti sul restauro e sulla critica architettonica. Roma: Bonsignori Editore, 1995.

CARBONARA, Giovanni. Questioni di principio e di metodo nel restauro dell'architettura, in Restauro. Quaderni di restauro dei monumenti e di urbanistica dei centri antichi, vol. VII, n. 36, 1978, p. 3-51.

CARBONARA, Giovanni. Restauro architettonico: principi e metodo. Roma: Carlo Mancosu Editore, 2012.

CHOAY, Françoise. A Alegoria do Patrimônio. São Paulo: Estação Liberdade / Ed. Unesp, 2001.

DE FUSCO, Renato. Dov'era ma non com'era. II patrimonio architettonico e l'occupazione. Firenze: Alinea, 1999.

DOURADO, Odete. Apresentação. In: VIOLLET-LE-DUC, Eugène Emmanuel. Restauro. $3^{\mathrm{a}}$ ed. rev. e ampl. Salvador: UFBA, 1994, p. 3-6.

GALLET, Yves. Après l'incendie. Notre-Dame de Paris: bilan, réflexions, perspectives. Bulletin monumental, Société Française d'Archéologie, Tomo 177-3, 2019, p. 211-218.

GAUSSUIN, Bérénice. Eugène Viollet-le-Duc: une oeuvre entre restauration et création. Apuntes, Bogotá, Colômbia, vol. 30, n. 2, 2017, p. 60-71. Disponível em: http://revistas.javeriana.edu.co/index.php/revApuntesArq/article/view/23422. Acesso em: 09 out. 2020.

GAUSSUIN, Bérénice. Viollet-le-Duc is back. Usages fragmentaires d'une oeuvre kaléidoscopique (1964-1980). Les Cahiers de la recherche architecturale urbaine et paysagère [on-line], n. 4, 2019, Disponível em: http://journals.openedition.org/craup/1559. Acesso em 09 out 2020. 
HERNÁNDEZ MARTÍNEZ, Ascensión. Restauración, transformación, reciclaje. La deriva de la disciplina más allá de los criterios consolidados, In: HERNÁNDEZ MARTíNEZ, Ascensión (Coord.). Conservando el pasado, proyectando el futuro. Tendencias en la restauración monumental en el siglo XXI. Zaragoza: Institución Fernando El Católico, 2016, p. 31-51.

ICOMOS. ICOMOS Guidance on Post Trauma Recovery and Reconstruction for World Heritage Cultural Properties. Paris, 2017 Disponível em: http://openarchive.icomos.org/1763/. Acesso em: 06 fev. 2021.

ICOMOS. Carta de Veneza. In: CURY, Isabelle (org). Cartas patrimoniais. Rio de Janeiro: IPHAN, 2004, p. .

ICOMOS France. Activités et réflexions 2019. Paris, 2020. Disponível em: http://france.icomos.org/resources/library/0/ICOMOSFrance Activites reflexions2019.pdf. Acesso em: 05 fev. 2021.

IRACE, Fulvio. Notre-Dame, il dilemma dei restauri tra autenticità o feticcio, II Sole 24 Ore. 17 abr. 2019. Disponível em: https://www.ilsole24ore.com/art/notre-damedilemma-restauri-autenticita-o-feticcio-ABXI2epB?refresh ce $=1$. Acesso em: 20 set. 2020.

JOKILEHTO, Jukka. A History of Architectural Conservation. The contribution of English, French, German and Italian thought towards an international approach to the conservation of cultural property. D. Phil Thesis, Institute of Advanced Architectural Studies, The University of York, 1986.

KÜHL, Beatriz Mugayar. A restauração de monumentos históricos na França após a Revolução Francesa e durante o século XIX: um período crucial para o amadurecimento teórico. Revista CPC. São Paulo, n. 3, p. 110-144, 2007. Disponível em: http://www.revistas.usp.br/cpc/article/view/15601/17175. Acesso em: 05 out. 2020.

KÜHL, Beatriz Mugayar. Ética na preservação no século XXI, In: HERNÁNDEZ MARTÍNEZ, Ascensión (Coord.). Conservando el pasado, proyectando el futuro. Tendencias en la restauración monumental en el siglo XXI. Zaragoza: Institución Fernando El Católico, 2016, p. 53-68.
MOREZZI, Emanuele. Idea, stile, dettaglio.Il progetto dela decorazione scultorea in Notre Dame de Paris e Pierrefonds. ROMEO, Emanuele (a cura di). Eugène Emmanuel Viollet-le-Duc. Contributi per una rilettura degli scritti e delle opere (18142014). Roma: WriteUp Site, 2019, p. 183-231.

NAPOLEONE, Lucina. La maturazione della categoria «Stile» in Viollet-le-Duc attraverso gli scritti e gli studi su Carcassonne (1844-1866). ROMEO, Emanuele (a cura di). Eugène Emmanuel Viollet-le-Duc. Contributi per una rilettura degli scritti e delle opere (1814-2014). Roma: WriteUp Site, 2019, p. 243-259.

NOUVEL, Jean. Notre-Dame, l'architecture et l'amnésie. Le Monde, 10 out 2020. Disponível em: https://www.lemonde.fr/idees/article/2020/08/10/jean-nouvel-notredame-I-architecture-et-l-amnesie 6048556 3232.html. Acesso em 13 out 2020.

OLIVEIRA, Mário Mendonça de; SANTIAGO, Cybèle Celestino. Viollet-le-Duc e o restauro de Notre Dame. Salvador: EDUFBA, $2^{\mathrm{a}}$ ed., 2019.

PANE, Andrea. Questões contemporâneas de restauro: una riflessione dall'Italia, In: SALCEDO, Rosío Fernández Baca; BENINCASA, Vladimir (org). Questões contemporâneas: patrimônio arquitetônico e urbano. Bauru, SP: Canal 6, 2017, p. 109-130.

PANE, Roberto. Considérations sur la Réunion d’experts tenue au siege de r'Unesco du 17 au 21 octobre 1949. Museum, vol. III, p.8-48, 1950.

POISSON, Olivier. Notre-Dame, du national au mondial. In: Quel avenir pour Notre-Dame?, Journée d'Études, Université de Bordeaux, 4 octobre 2019. Disponível em: https://www.academia.edu/43267191/Notre Dame du national au mondial 2019 ?email work card=title. Acesso em: 05 fev. 2021.

POULOT, Dominique. Notre-Dame de Paris: Un espace civique du patrimoine après la catastrophe. Bulletin Monumental, Société Française d'Archéologie, Tome 1774, 2019, p. 375-381.

RODRIGUES, Angela Rosch. Da restauração à reconstrução: impasses conceituais nos debates patrimoniais do século XX e seus reflexos na contemporaneidade, In: Anais do 1ํㅗmpósio Científico ICOMOS Brasil, Belo Horizonte, 2017. 
VIOLLET-LE-DUC, Eugène Emmanuel. Restauração. Apresentação e tradução de Beatriz Mugayar Kühl. São Paulo: Ateliê Editorial, 2000.

VIOLLET-LE-DUC, Eugène Emmanuel.. Restauro. $3^{\text {a }}$ ed. rev. e ampl. Apresentação, tradução e notas por Odete Dourado. Salvador: UFBA, 1994.

UNESCO. Décision 43 COM 7B.82, presse en la 43e session du Comité du patrimoine mondial (43 COM), 2019. Disponível em: http://whc.unesco.org/fr/decisions/7515. Acesso em: 05 fev. 2021. 